\title{
DESENVOLVIMENTO DE GOMA MEDICAMENTOSA DE GELATINA CONTENDO EXTRATO AQUOSO DAS CASCAS DOS FRUTOS DA JABUTICABEIRA
}

\author{
Carolynne Pazini Schaydegger ${ }^{1}$ \\ Stela Givisiez Melo Fernandes ${ }^{2}$ \\ Wesley Careri Müller ${ }^{3}$ \\ Juliana Aparecida Severi ${ }^{4}$ \\ Janaina Cecília Oliveira Villanova ${ }^{5}$
}

Resumo: O uso de fitoterápicos foi incorporado ao Sistema Único de Saúde por meio do Decreto № 5.813, de 22 de junho de 2006 e, nas últimas décadas, o interesse da população pelo uso de produtos farmacêuticos preparados a partir de plantas medicinais tem aumentado significativamente. Inúmeros estudos relatam o sucesso do uso de extratos no preparo de medicamentos, cosméticos e produtos de higiene. Aos extratos das folhas, caules e frutos da Plinia cauliflora, conhecida como jabuticaba, são atribuídas atividades antibiótica e antifúngica. Neste contexto, o presente trabalho teve como objetivo principal a obtenção de extrato aquoso das cascas dos frutos da jabuticabeira, visando posterior incorporação em gomas medicamentosas, com o intuito de obter preparações antissépticas. Após o preparo, o extrato foi submetido à triagem fitoquímica, que confirmou a presença de taninos e flavonóides. Após obtenção da base, o extrato foi incorporado e as gomas medicamentosas foram obtidas por moldagem. Os produtos finais apresentaram textura e sabor agradável e cumpriram com as especificações para o ensaio de médio.

Palavras-chave: Plinia cauliflora; Gomas medicamentosas; Antisséptico bucal.

\footnotetext{
${ }^{1}$ Farmácia/Universidade Federal do Espírito Santo - UFES, Brasil. E-mail: carol_pazine@hotmail.com.

2 Farmácia/Universidade Federal do Espírito Santo - UFES, Brasil. E-mail: stelinhaferandesj@gmail.com.

${ }^{3}$ Farmácia/Universidade Federal do Espírito Santo - UFES, Brasil. E-mail: wesley.muller@outloock.com.

${ }^{4}$ Farmácia/Universidade Federal do Espírito Santo - UFES, Brasil. E-mail: juseveri@yahoo.com.br.

${ }^{5}$ Farmácia/Universidade Federal do Espírito Santo - UFES, Brasil. E-mail: pharmacotecnica@yahoo.com.br.
} 